\title{
Joaquim Cardozo ou pequenas imagens do deserto
}

Manoel Ricardo de Lima ${ }^{1}$

Resumo: O texto trata, perseguindo uma série imprevista e questões políticas, uma ideia de procedimento do pensamento de Joaquim Cardozo que se engendra a partir do conceito de deserto. A série, rapidamente, se elabora, entre outras coisas, entre poemas de Joaquim Cardozo, trabalhos de Richard Long e João Cabral de Melo Neto em torno do traço, da linha e do assombro.

Palavras-chave: Joaquim Cardozo, linha, imagem, pensamento, política, deserto

Eu me satisfaço com minha casa e o deserto. [...]

O que vou fazer o dia todo? Vou estudar o deserto,

por exemplo, em longas caminhadas ao amanhecer,

antes de tudo se tornar insuportavelmente quente.

Amós $\mathrm{Oz}$

O pensamento de Joaquim Cardozo, do cálculo ao poema, das artes visuais à arquitetura, do teatro ao ensaio etc., aparece como um jogo incessante que se move num plano interrogativo de imanência da política: como criar algo propositivo à história sem aderir a nenhum peso imediatamente institucional? Uma espécie de abertura de flancos por dentro das ruínas do que se toma, num modelo, como modernismo brasileiro e nacionalizante, arejandoo, ou tensionando o que se poderia ainda inventar. Roland Barthes aponta um gesto: "a escritura, esta é integralmente 'o que está por inventar', a ruptura vertiginosa com o antigo sistema simbólico, a mutação de todo um flanco da linguagem" (BARTHES: 2004, p. 197). Pode-se ler a partir desse apontamento que o pensamento de Joaquim Cardozo, o que Maria

\footnotetext{
${ }^{1}$ Professor da Escola de Letras e do PPG em Memória Social, da Universidade Federal do Estado do Rio de Janeiro (UNIRIO), Rio de Janeiro, Brasil. Publicou, entre outros, Pasolini: retratações [7Letras, 2019, com Davi Pessoa], avião de alumínio [Quelônio, 2018, com Júlia Studart], Livros de Guerra [Sem Titulo Arte, 2018], Maria quer o mundo [Edições SM, 2015, para crianças], Geografia Aérea [7Letras, 2014], Cuando todos los accidentes suceden [Kriller 71, 2014], As mãos [7Letras, 2003/2012], Jogo de Varetas [7Letras, 2012], A forma-formante: ensaios com Joaquim Cardozo [EdUFSC, 2014] e Falas Inacabadas [Tomo, 2000, com Elida Tessler]. Coordena a edição da Poesia de Ruy Belo no Brasil [7Letras] e a Coleção Móbile de mini-ensaios [Lumme Editor]. E-mail: manoelrl@uol.com.br
} 
da Paz Ribeiro Dantas, uma de suas melhores leitoras, também sustenta, aparece como "um movimento de formas e cores em que quase não se distingue o ver do que é visto." (DANTAS: 2003, p. 14)

O que salta desse impasse, ver / visto, é a imagem do deserto, que não é senão, ao mesmo tempo, para retomar certo paradigma marxista, uma impossibilidade e uma incapacidade de decifração. Todo o trabalho de Joaquim Cardozo é uma beira de mundo, um bordejamento que se elabora como uma potência de contorno às estruturas socialmente determinadas pela pedagogia moderna da mercadoria. Contra isto vem o deserto, espaço infinito que, em vários sentidos, se insurge desde a figura terminantemente silenciosa de Joaquim Cardozo, figura que é um esboço de sua mera biografia, quase desconhecida e, muito mais, no que comparece traçado entre a sombra, quando a existência se refrata alargando os empenhos da cultura, e uma anamnese esvaziada, uma paisagem do instante, quando é o perigo que anuncia radicalmente a vida.

No livro Mundos Paralelos, de 1970, temos um bom exemplo da impossibilidade de demarcação das imagens que Joaquim Cardozo infere, porque persegue, por exemplo, linhas que projetam um sentido de desaparecimento daquele que as escreve, que diz, para anular o que se diz e a quem se diz, lançando essas linhas ao infinito e impensado do deserto. O que sobra não é nem sequer contorno, mas, se algo ou alguma coisa, é apenas uma transparência. Primeiro, no poema Balada Para as Damas de um Outrora Sem Tempo, quando anota:

\author{
Destino! Uma sombra na pedra! \\ Uma sombra? De quê? \\ Propriamente não sei \\ saberei. \\ - Sombra de um nuncamente \\ Que na pedra erguerei:
}

Sombra - escultura de Jamais.

(CARDOZO: 1970, p. 159)

Depois, no poema Os Mundos Paralelos, em duas passagens,:

No que aqui é macio no paralelo áspero

Mundo paralelo!

Gláuks: Revista de Letras e Artes - jul./ dez. 2019 - Vol 19, $N^{o}$ 2, ISSN 2318-7131 
afogar

Nele é que vou me apagar, me sumir, me perder,

Me esconder, para sempre, no esquecer.

Noitemente amanhecer.

Todos os meus atos são atos reflexos

No projeto espelho tempo/espaço, no fechado não denso.

Correspondência injetiva, de primente, fria, de interno entorno.

(re)

(CARDOZO: 1970, p. 161)

Note-se, assim, o caso do uso de alguns advérbios inventados, como "nuncamente" ou "noitemente", ou o recurso simples da duplicação dos prefixos de e re, justapostos, para montar duas palavras numa só: "deprimente", "reprimente". Esta singularidade de uma ideia de transparência que Joaquim Cardozo imprime, pode remeter, numa série imprevista, ao trabalho do artista inglês Richard Long (1945-), um dos criadores da Land Art, quando este propõe uma leitura do deserto como a imagem de uma paisagem sem referente; o deserto aparece na linha construída com os pés para separar o inseparável e impensável da terra, um confim. Dois trabalhos de Long, um feito no deserto do Saara, em 1988, Dusty Boots Line, e o outro no Peru, Walking a Line, em 1972, mostram a linha traçada como um sulco, imagem de vinco - aquilo que corta a areia do deserto abrindo-o ao meio, num acesso de rasgo -, através do gesto repetido de riscar o chão, arrastando a sola das botas de calçar como se projetasse, assim, também, uma brincadeira de criança: separar o espaço, reabrir o tempo:

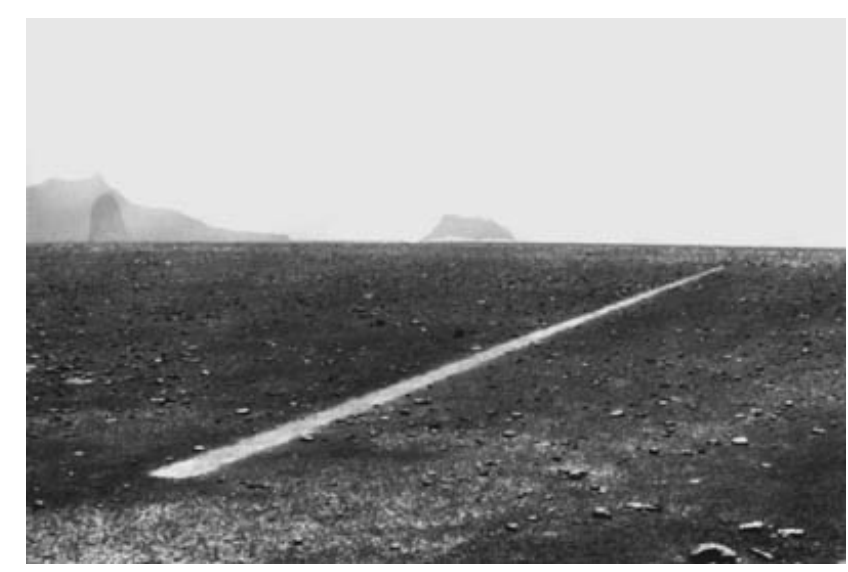

Figura 1: Dusty Boots Line, Saara, 1988.

Gláuks: Revista de Letras e Artes - jul./ dez. 2019 - Vol 19, No 2, ISSN 2318-7131 


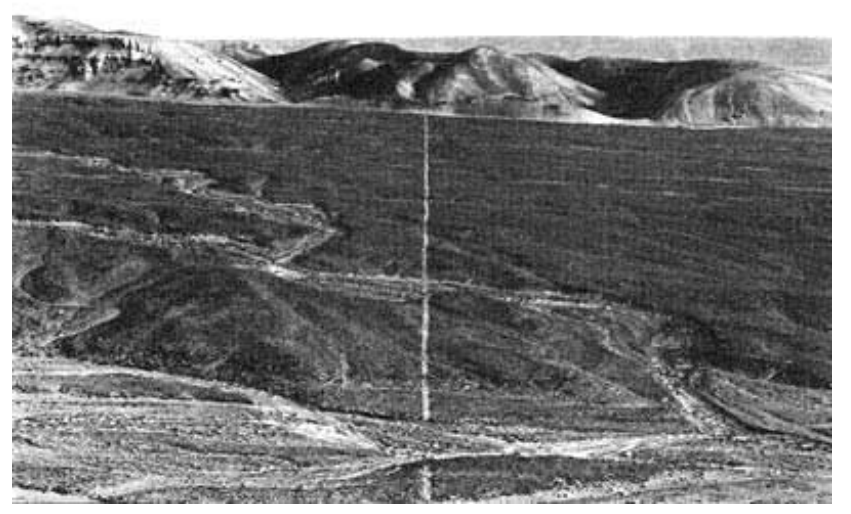

Figura 2: Walking a Line, Peru, 1972.

É uma paisagem que se dilata, tal qual uma deriva do sentido imediato, alargando e expandido a ideia de sentido, naquilo que Maurice Blanchot propõe como deserto (ao falar sobre os profetas e a palavra profética, o que "se mistura ao tumulto da história", a "história que por momentos se tornou a impossibilidade da história" - BLANCHOT: 1994, p. 89) e, principalmente, para confirmar que o deserto é um fora, uma "saída sem saída": "Nada de simbólico, nada de figurado no que dizem, tal como o deserto não é uma imagem, mas o deserto da Arábia, lugar geograficamente situável, que é também ao mesmo tempo a saída sem saída onde sempre desemboca o êxodo.” (BLANCHOT: 1994, p. 89)

O que se percebe, mesmo que lentamente, é que esses trabalhos de Richard Long movem um desaparecimento, primeiro por causa do clima natural desses desertos, como os fortes ventos, por exemplo, depois porque as linhas são reforçadas com pedra, lama, areia, cascalho, para compor uma espécie de texto impossível, esculturas de nada, que não demarcam territórios, fronteiras, nacionalidades, posses etc. Retira-se daí toda ideia de monumento e toda memória fixa que se desampara também com um recurso simples do corpo, o de uma caminhada. Isto é uma possibilidade e uma abertura, um desenho de sombra, um vestígio lançado sobre uma planície como se fosse uma assombração. Em uma das quadras do poema $A$ várzea tem cajazeiras, Joaquim Cardozo anota uma espécie de palavra profética e assombrada a partir do "nervo de sua obsessão lírica - a várzea” (DANTAS: 2003, p. 16), como indica Maria da Paz:

\footnotetext{
Nessa várzea sou planície,

Vaga dimensão dormente;

Tendida no chão conforme
} 
Sou de mim sombra somente.

(CARDOZO: 2010, p. xx)

Nessa geografia desfixada, mas também geografia-osso, porque toda ela traçada com o corpo e sua sombra, desfaz-se a dimensão institucionalizada daquilo que ocupa um espaço estratégico de significados e enunciados; essa linha escrita para apagar-se, arma-se numa afirmativa da negação - sombra, assombração -, naquilo que nubla todo núcleo das coisas, todo o centro de tudo, para deixá-lo vazio ou minimamente disponível. É como a Muhme, palavra alemã em desuso que significa tia, que Walter Benjamin lembra numa passagem acerca da força dos mal-entendidos que modificam o mundo através da imaginação, do sentido desconhecido que provoca o desvario da assombração: “o Mudo, o Movediço, o Tormentoso, que, como a nevasca nas bolas de cristal, nubla o núcleo das coisas". (BENJAMIN: 1987, p. 100)

Isto não deixa de ser a percepção de um deserto extimo, quando o deserto é um vazio, o que Deleuze recupera em seu texto a partir de T. E. Lawrence, "um dos maiores paisagistas da literatura" (1997, p. 131), A honra e a Glória: T.E. Lawrence: "uma disposição subjetiva infinitamente secreta, que não se confunde com um caráter nacional ou pessoal e que o leva para longe de seu país, sob as ruínas do seu eu devastado.” (1997, p.132) Deleuze diz que o deserto é uma percepção íntima, mas é, ao mesmo tempo, um aberto para a luz, para a revolta - logo seria também uma extimidade -, e projeta um agenciamento com o mar de Herman Melville, de Benito Cereno e principalmente Ahab: "um oceano íntimo desconhecido dos marinheiros" (1997, p. 132), e faz perguntas importantes acerca dessa necessidade e desse desejo de habitar o deserto: "De que modo viver e sobreviver no deserto como livre subjetividade? (...) De que modo 'voltar a ser um homem como os demais acorrentando-me aos meus semelhantes?' Como viver e sobreviver num exército, enquanto 'tipo' anônimo objetivamente determinado nos seus mínimos detalhes? (1997, p. 138). Para Deleuze há uma disposição em Lawrence - "o dom de fazer viver apaixonadamente as entidades no deserto, ao lado das pessoas e das coisas, ao ritmo irregular do passo dos camelos" (1997, p. 135) - que, assim como o traçado de Richard Long no deserto, lança-se até o pensamento de Joaquim Cardozo, principalmente a partir da ideia radical para remontar imagens tênues para "fabricar o real e não de responder a ele". (1997, p. 134) É que, diz Deleuze, “por trás da imagem não há nada, uma 'ausência de ser', um vazio que dá testemunho de um eu dissolvido. Por trás das imagens não há nada, exceto o espírito que as contempla com estranha frieza, mesmo que

Gláuks: Revista de Letras e Artes - jul./ dez. 2019 - Vol 19, No 2, ISSN 2318-7131 
sejam sangrentas e dilaceradas." (1997, p. 134) Tem-se, assim, em Joaquim Cardozo, Richard Long e o Lawrence de Deleuze, máquinas de fabricar gigantes, fabuladores de impressão severa, os que veem através da bruma, das formas e das cores. Desse modo, Deleuze confirma:

[...] Lawrence diz que vê através de uma bruma, que não percebe imediatamente as formas nem as cores e que só reconhece as coisas no contato imediato com elas; que não é muito homem de ação, que se interessa pelas ideias mais que pelos fins e seus meios; que quase não tem imaginação e não gosta dos sonhos (...). Mas o que o inspira e arrasta é ser um "sonhador diurno", um homem perigoso de verdade, que não se define nem pela relação com o imaginário ou os sonhos, mas apenas pela força com a qual projeta no real as imagens que soube arrancar de si mesmo (...).

(DELEUZE: 1997, p. 133)

O ponto de fuga é uma saída de um topos para um tropos numa imagem retabular, que Maria da Paz Ribeiro Dantas lê, no pensamento de Joaquim Cardozo, como uma "paixão pelo que há de local e ao mesmo tempo cósmico na geografia física e humana - seja do interior e/ou do litoral - de sua terra e de sua gente" (DANTAS: 2003, 09) e que se desterritorializa num "espaço de onde fala é a natureza - certa natureza -, com seus sítios indígenas perdidos no tempo, [...], descobertos a partir de situações sem qualquer atrativo para mentes e percepções menos aguçadas.” (DANTAS: 2003, p. 09) É a região de um país inventado por Joaquim Cardozo, um Nordeste reconfigurado em cosmogonias, sem cercas, apontado para um lime assombrado que, por sua vez, tende a reconfigurar o espaço da natureza numa proximidade intensa ao que pode ser "construído à percepção de uma arquitetura cósmica" (DANTAS: 2003, p. 73). E ela completa:

[...] é dali, de regiões àquela época (década de 1920) praticamente não desbravadas, que de repente assoma um mistério, um enigma, como se antenas captassem certo arrepio de espanto, proveniente de algum campo magnético; e a sensação de que estamos diante do mistério (....)." (DANTAS: 2003, p. 09). 
João Cabral de Melo Neto salienta os sentidos dessa leitura de Maria da Paz Ribeiro Dantas, ao apresentar a importância do pensamento de Joaquim Cardozo para ele. Na entrevista concedida aos Cadernos de Literatura Brasileira (do Instituto Moreira Salles, $\mathrm{n}^{\mathrm{o}}$ 1, Rio de Janeiro, março de 1996), diz:

Quem também teve influência sobre mim foi Joaquim Cardozo, calculista de Brasília e de outros projetos de Niemeyer. Ele era poeta também. Fomos grandes amigos. Quando eu estava no Rio me encontrava com ele diariamente. É curioso isso, nós nos conhecemos no Recife, mas só nos aproximamos mais quando eu vim para o Rio, nos anos 40.

Antes, em dois poemas, João Cabral já reacendera a importância de seu conterrâneo e contemporâneo de uma maneira irresoluta e sem indicação prévia. Publicados em Educação Pela Pedra [1965], o primeiro, Habitar o Tempo; e o segundo, Bifurcados de Habitar o Tempo, que é um desdobramento convulso e vocabular do primeiro, quando repetir é um diferimento, que curiosamente antecede ao poema de onde se desdobra:

\section{Habitar o tempo}

Para não matar seu tempo, imaginou: vivê-lo enquanto ele ocorre, ao vivo; no instante finíssimo em que ocorre, em ponta de agulha e porém acessível; viver seu tempo: para o que ir viver num deserto literal ou de alpendres; em ermos, que não distraiam de viver a agulha de um só instante, plenamente. Plenamente: vivendo-o de dentro dele; habitá-lo, na agulha de cada instante, em cada agulha instante: e habitar nele tudo o que habitar cede ao habitante.

E de volta de ir habitar seu tempo: ele corre vazio, o tal tempo ao vivo; e como além de vazio, transparente, o instante a habitar passa invisível.

Portanto: para não matá-lo, matá-lo; matar o tempo, enchendo-o de coisas; em vez do deserto, ir viver nas ruas onde o enchem e o matam as pessoas; pois como o tempo ocorre transparente e só ganha corpo e cor com seu miolo (o que não passou do que lhe passou), para habitá-lo: só no passado, morto.

\section{Bifurcados de 'Habitar o tempo'}

Viver seu tempo: para o que ir viver num deserto literal ou de alpendres; em ermos, que não distraiam de viver a agulha de um só instante, plenamente. Exceção aos desertos: o da Caatinga, que não libera o homem, como outros, 
para que ele imagine ouvir-se mundos

ouvindo-se a máquina bicho do corpo;

Ele ocorre vazio, o tal tempo ao vivo;

para que, só e entre coisas de vazio,

e, como além de vazio, transparente,

de vidro igual ao do que não existe,

habitar o invisível dá em habitar-se:

o homem, como lhe sucede num deserto,

a ermida corpo, no deserto ou alpendre.

imagine sentir outras coisas ao sentir-se;

Desertos onde ir ver para habitar-se,

embora um deserto, a Caatinga atrai,

mas que logo surgem como viciosamente

ata a imaginação; não a deixa livre,

a quem foi ir ao da Caatinga nordestina:

para deixar-se, ser; a Caatinga a fere

que não se quer deserto, reage a dentes.

e a ideia-fixa: com seu vazio riste.

(MELO NETO: 1994, p. 365 e p. 354-355)

É o gesto da repetição, que está por todo esse livro de João Cabral, que remonta e projeta um sentido expandido à ideia de deserto. Desde as quatro partes intituladas numa nomeação austera e quadrada, os nortes de uma mesma geografia-osso: Nordeste (a), Não Nordeste (b), Nordeste (a), Não Nordeste (a). É possível que se possa tomar este procedimento, o de nomear as partes do livro com uma variação do nome Nordeste, como uma importância às avessas para de Joaquim Cardozo, quando este elabora e faz um alargamento por dentro das figurações que este mesmo nome provoca em sua poesia. João Cabral, por sua vez, manifesta uma outra maneira de circunstância entre vínculo e nome, mais próxima de uma concretude entre o nome e a coisa significada / e a coisa significada e nome que a anuncia, sempre carregando marcas suspeitas tanto do nome quanto da coisa. Em alguns outros poemas desse livro, essas marcas sempre aparecem num quadrado repetido: $O$ Mar e $O$ Canavial / O Canavial e o Mar; Coisas de Cabeceira, Recife / Coisas de Cabeceira, Sevilha; The Country of the Houyhnhnms / The Country of the Houyhnh (outra composição); A Urbanização do Regaço / O Regaço Urbanizado etc. E assim, como se pode ler tanto num poema quanto no outro, o que vai comparecer diferente é uma aproximação da perspectiva do deserto como desmesura, como um instante íntimo e ao mesmo tempo extimo de perigo, uma assombração, um encontro inesperado com a assombração, num devir da história e num mover-se entre lá e cá de instantes finíssimos, e para habitá-lo só no passado, morto, como aquele que se imagina deserto, sempre numa outridade e sem um si mesmo: deserto assombrado, reagindo a dentes.

As linhas da escritura de João Cabral, sempre plurais e para muito além da ideia de lugar, como desejo, sugerem uma terra que se desvincula do nome e que também se faz na

Gláuks: Revista de Letras e Artes - jul./ dez. 2019 - Vol 19, $N^{o} 2$, ISSN 2318-7131 
linha imperceptível do perigo a partir de imagens que potencializam uma relação efetiva com o deserto, e isto se daria num procedimento a que toma como "a ação do sono". Em seu ensaio Considerações sobre o poeta dormindo procura sugerir uma zona de sombra, uma zona de lama preta, que lança o homem numa luta cósmica com seus desertos. Tem-se aí uma fuga do tempo, uma ideia da abstração do tempo, uma "máquina abstrata", no dizer de Deleuze, e que João Cabral confirma ao lembrar Jorge de Lima chamando a isto de "a pedra de toque do verdadeiro poeta": na "ideia de abstração do tempo, de 'fuga' do tempo, que Jorge de Lima considera 'a pedra de toque do verdadeiro poeta', e que no sono se reveste de um caráter, já não mais 'ideal', de pensamento, mas efetivo.” (1994, p. 687). O sono, "esta mesma tranquilidade com que se morre" (1994, p. 688), é "uma incursão periódica no eterno, que restabelece no homem esse equilíbrio que no poeta há de ser, necessariamente, um equilíbrio contra o mundo, contra o tempo." (1994, p. 688)

Em João Cabral o que se lê é uma escassez de ser, como ele mesmo sugere, através do deserto e do deserto-desfixado da caatinga: quem reage a dentes? A pergunta que ainda se poderia fazer a partir desse texto de João Cabral é: o que resta a poesia desde a modernidade ao presente quando o direito ao sono do deserto parece é também um hospedeiro dos moveres do capital? Não há muita diferença entre isto que João Cabral sugere e o problema que Walter Benjamin anota (a partir de Charles Baudelaire) para o desaparecimento da poesia - como experiência - já no século 19 e que, agora, com muita fragilidade de argúcia e pensamento alguns teóricos tentar ler como um estilhaço do que chamam de "capitalismo tardio". Antes, e com força, João Cabral reclama um direito ao sono: "Apenas, fecunda-a com o seu sopro noturno - o hálito da própria poesia em todas as épocas." (MELO NETO: 1994, p. 688) Essa fecundação pode ser lida como um vínculo ao deserto, ao assombro do deserto. E é no sono (fulguração de um desejo e de uma potência efetivos para a existência), sem objetivos, travessia e presença, que se tem um repouso às imagens sem referente, neutras e abertas.

Todo esse apontamento para perseguir a leitura que João Cabral fez de Joaquim Cardozo: a de que o poema é sempre um contra, um desequilíbrio da imagem que existe apenas para morrer em seguida, como um desejo, uma profanação, um esquecimento provocado pela assombração por dentro das imagens, labirinto de traças, zona de lama preta, acontecimento branco etc. É num poema de Joaquim de seu primeiro livro, Poemas (1947), Poema do homem dormindo, que estão as pistas dessa leitura:

O homem que dorme é um menino.

Gláuks: Revista de Letras e Artes - jul./ dez. 2019 - Vol 19, $N^{o}$ 2, ISSN 2318-7131 
O homem que dorme é mais puro que um menino, é um anjo.

O seu rosto parece uma noite de lua,

Ele tem nas mãos o espírito úmido de um lago.

Ele tem sob os olhos a sombra tranquila das coisas.

No leito em que durmo não quero mulheres,

Elas agitam o meu corpo e perturbam os meus sonhos.

Para que macular assim a pureza encantadora do sono?

O homem que dorme está só,

Vive num mundo só dele, num mundo diferente

Onde qualquer lei científica pode ser alterada.

O homem que dorme conhece o milagre.

O homem que dorme imagina paraísos.

O homem que dorme é melhor do que os mortos.

(CARDOZO: 1947, p. 08)

O poema antecipa a ladainha - entre tença e renga -, como uma desobra de arenga, para levar a um termo e a um começo, num qualquer "alhures", como em Hölderlin, e num qualquer "nenhures", convite ao sono traçado numa linha que, se supostamente existente, também supostamente apagada, possibilita "sob os olhos a sombra tranquila das coisas" entre ver e visto. Silvina Rodrigues Lopes afirma que "o homem é para além da sua sujeição de sujeito, é-se impossivelmente na divisão que o outra e que se permite que se diga, com Sófocles, na Antígona: "Há muitas coisas estranhas (espantosas), mas nada há mais estranho (espantoso) do que o homem". (LOPES: 2003, p. 165) Assim, e sempre de modos diferentes, se pode começar a ler as questões que giram em torno do deserto assombrado no pensamento de Joaquim Cardozo, tendo sempre à mão que, para ele o homem que dorme é um menino, o homem que dorme é mais puro que um menino, é um anjo, algo para além do humano, como o desejo que se equilibra entre o animal e o humano, um aberto.

\section{Referências bibliográficas}

Gláuks: Revista de Letras e Artes - jul./ dez. 2019 - Vol 19, No 2, ISSN 2318-7131 
BARTHES, Roland. O Rumor da Língua. Trad. Mário Laranjeira. São Paulo: Martins Fontes, 2004.

BENJAMIN, WALTER. Rua de Mão Única. Trad. Rubens Rodrigues Torres Filho et al. São Paulo: Brasiliense, 1987.

BLACHOT, Maurice. O Livro por Vir. Trad. Maria Regina Louro. Lisboa: Relógio D’água, 1984.

CARDOZO, Joaquim. Poesia completa e prosa. [Org. Everardo Norões]. Rio de Janeiro: Nova Aguilar, 2010.

DANTAS, Maria da Paz Ribeiro. Joaquim Cardozo - contemporâneo do futuro. Recife: Ensol, 2003.

DELEUZE, Gilles. Crítica e Clínica. Trad. São Paulo: Editora 34, 1997.

MELO NETO, João Cabral de. Poesia completa. Rio de Janeiro: Nova Aguilar, 1995.

LOPES, Silvina Rodrigues. Exercícios de Aproximação. Lisboa: Vendaval, 2003. 